\title{
Measurement of influence geometry of floor convector on his performance
}

\author{
T.Greššák ${ }^{1}$, A. Kapjor ${ }^{1}$, J. Hužvár ${ }^{1}$ \\ ${ }^{1}$ University of Žilina, Departure of Power Engineering, Univerzitna 1, 01026 Žilina, Slovakia
}

\begin{abstract}
The report deals with experimental measurement of influence geometry bath floor convector on his performance in the thermostatic chamber in natural convection. Purpose is to find influence of slope bath of floor convector on his performance.
\end{abstract}

\section{Introduction}

The floor convectors are heating elements used in places where is necessary to install heating elements (radiators) with low overall height, respectively, when these bodies need to be placed in the floor of the building structure. To achieve the greatest thermal performance of floor convectors with natural convection, was carried out experimental measurements of influence geometry of tub on thermal performance of floor convector performed in a thermostatic chamber.

\section{Construction of floor convector}

Floor convector is composed of elements such as grid of convector (wooden or metallic), facing frame and tub of convector. The most important part is the actual heat exchanger which is placed in the tub. The heat exchanger consists of a copper tube, to which they are specially shaped pressed aluminum plates, to achieve high thermal performance. Exchangers are usually on one side ending with an internal diameter of nuts $G 1 / 2$ " and the other side is welded air vent. All this parts we can see at figure 1 .

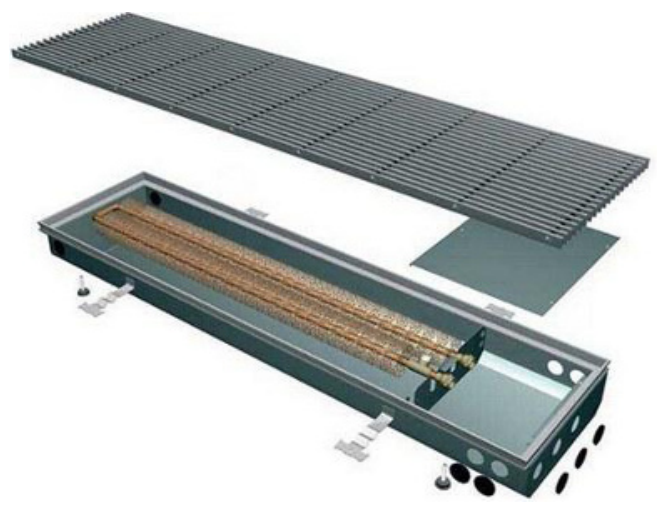

Fig. 1. Elements of floor convector

\section{Heat transfer in the floor convector}

The process of heat transfer by floor convector with natural convection from the medium to surrounding air can be divided into (figure 2):

1. heat transfer from hot water to the tube wall

2. heat conduction through the wall of tube and heat conduction in a rib (conduction)

3. heat transfer from the outer tube wall and heat transfer from the wall of rib to free air with natural convection

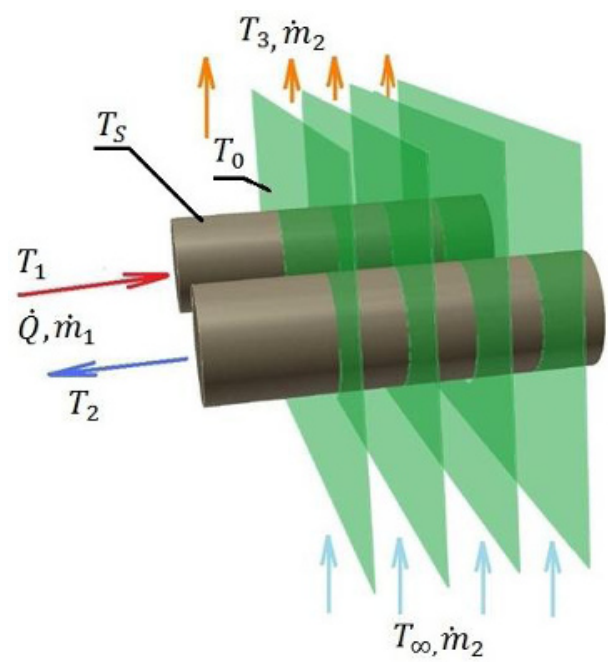

Fig. 2. Heat transfer of floor convector from medium to surrounding air.

The solution of this heat transport from the floor convector with natural convection can be based on analyzes of basic conservation equations (mass, energy, momentum) and state equations describing the 
thermodynamic state of the gas flow to the calculation of losses in the flow, also on heat transfer equations and relations for the properties of substances. Because this whole process of heat transfer from the floor convector to the surrounding air is carried out in a tub of convector, we detected what impact had the tub of floor convector on his performance.

\section{Geometry optimization of tub floor convector}

Themselves experimental measurements were performed on a sample of the floor convector, type BK 2E/270-12-2000 with design parameters: dimensions of the tub $270^{\mathrm{x}} 112^{\mathrm{x}} 2000 \mathrm{~mm}$, length of ribbed surface 1750 $\mathrm{mm}$, height of the rib $60 \mathrm{~mm}$, length of the rib $122 \mathrm{~mm}$, rib thickness $0.3 \mathrm{~mm}, 4 \mathrm{~mm}$ spacing of the ribs and tube diameter $18 \mathrm{~mm}$. Temperature of heating medium (temperature gradient) was $75 / 65^{\circ} \mathrm{C}$ and temperature of surrounding air was $20^{\circ} \mathrm{C}$. The floor convector was placed on the back wall of the thermostatic chamber. In this measurement was investigated most advantageous tilt of the front and back part of the tub floor convector on his thermal performance.

First, we changed the front part of the tub and in the range from 0 degree, when the front part of the tub was completely open to 90 degrees, when it was completely closed. Gradually, were made the measurements for $0^{\circ}$, $15^{\circ}, 30^{\circ}, 45^{\circ}, 60^{\circ}, 75^{\circ}$ and 90 degrees tilt of the front tub. For these optimizations were done Graph 1, which shows the dependence of performance on the tilt of front part of convector. The graph indicates that at 0 degree tilt (when the front of the of convector tub is fully open), was highest performance of floor convector. Where for tilt of 90 degrees (front tub fully closed), was the lowest performance of convector.

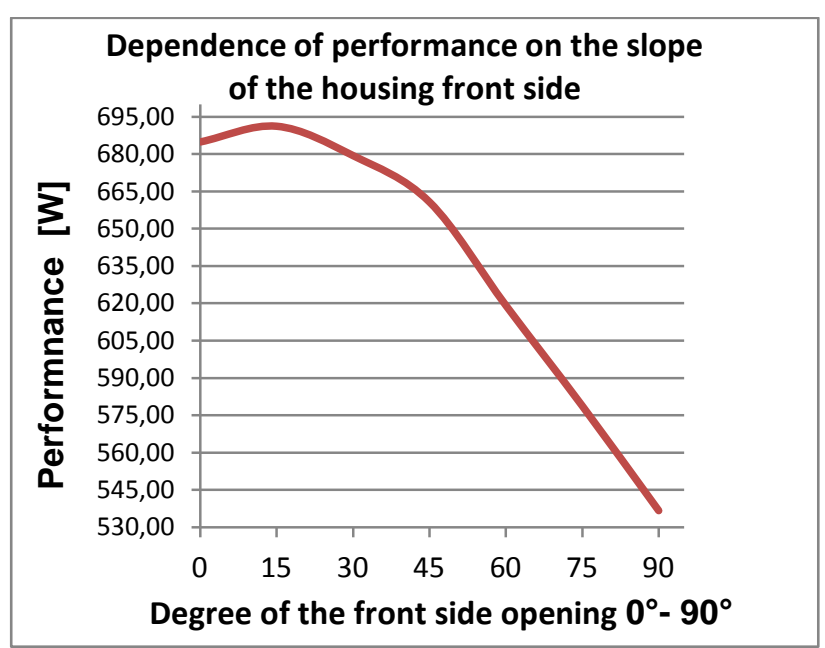

Graph 1 Dependence of the floor convector performance on the slope of the housing front side

After making changes to tilt of front part tub, in the same way we changed the tilt of the back part of tub. On Graph 2 we can analogy see, that the performance of floor convector is the highest when is fully open $\left(0^{\circ}\right.$ tilt of tub, and lowest when is fully close. On graph 3 we can see the difference of the performance in tilt of the front and back part of tub floor convector. This difference is caused by the fact, that when you open the back part of the tub, the heat transmitted into surrounding area, wrap the wall of thermostatic chambers, which is cooler than surrounding air. This way occur the mixing of warm air from the convector and the cooler wall, and so created beliefs, which has the effect of reducing thermal performance. Formation of these viruses can be seen in figure 3, where we by CFD simulation in ANSYS 12.0 created a model of floor convector. Figure 3 shows the trajectory of the airflow with velocity contours, which is noticeable formation of beliefs in area of wall thermostatic chamber.

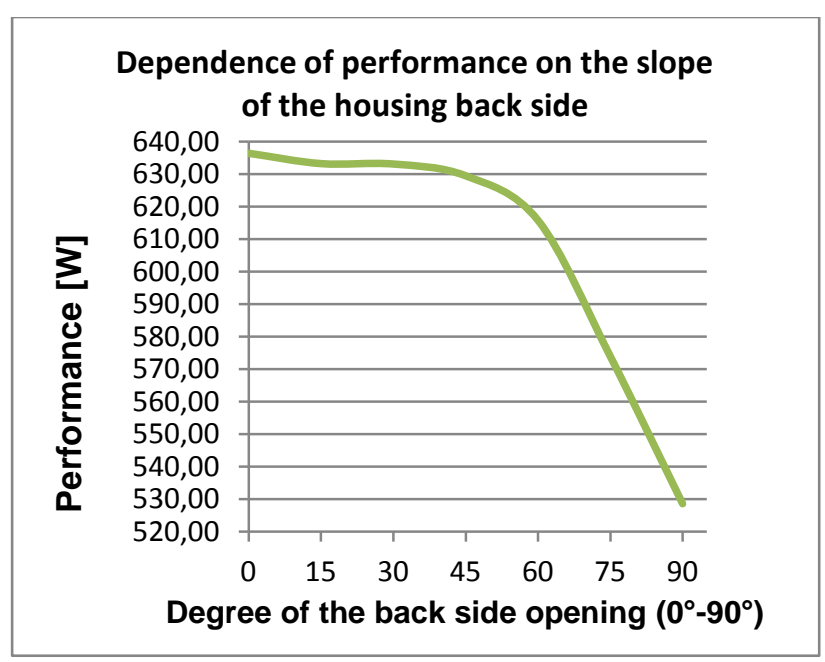

Graph 2 Dependence of the floor convector performance on the slope of the housing back side

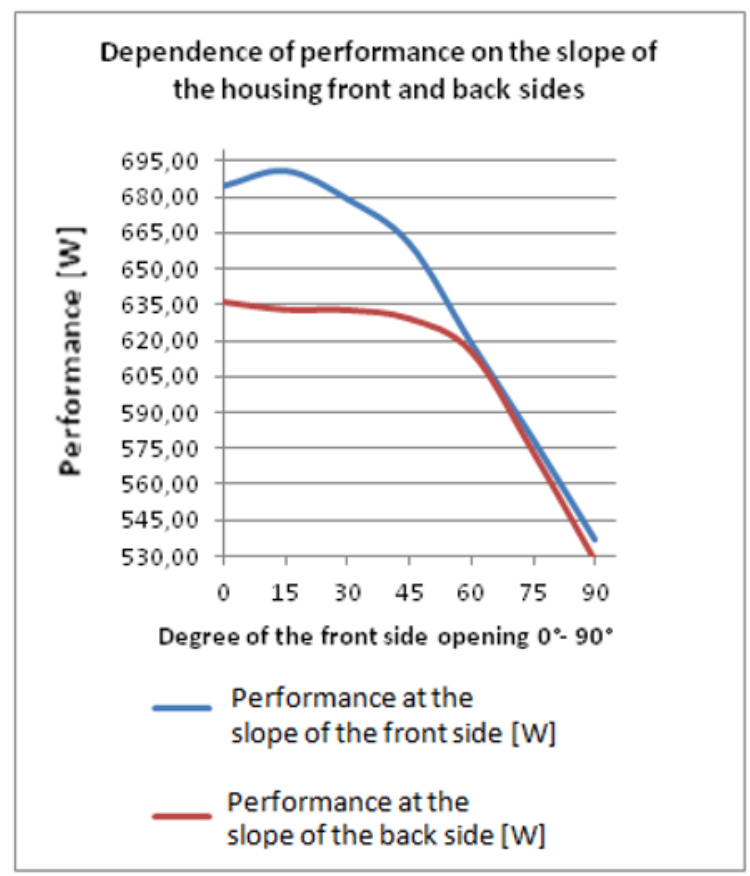

Graph 3 Comparison of the floor convector performance in dependence on the slope

of front and back sides of the housing 


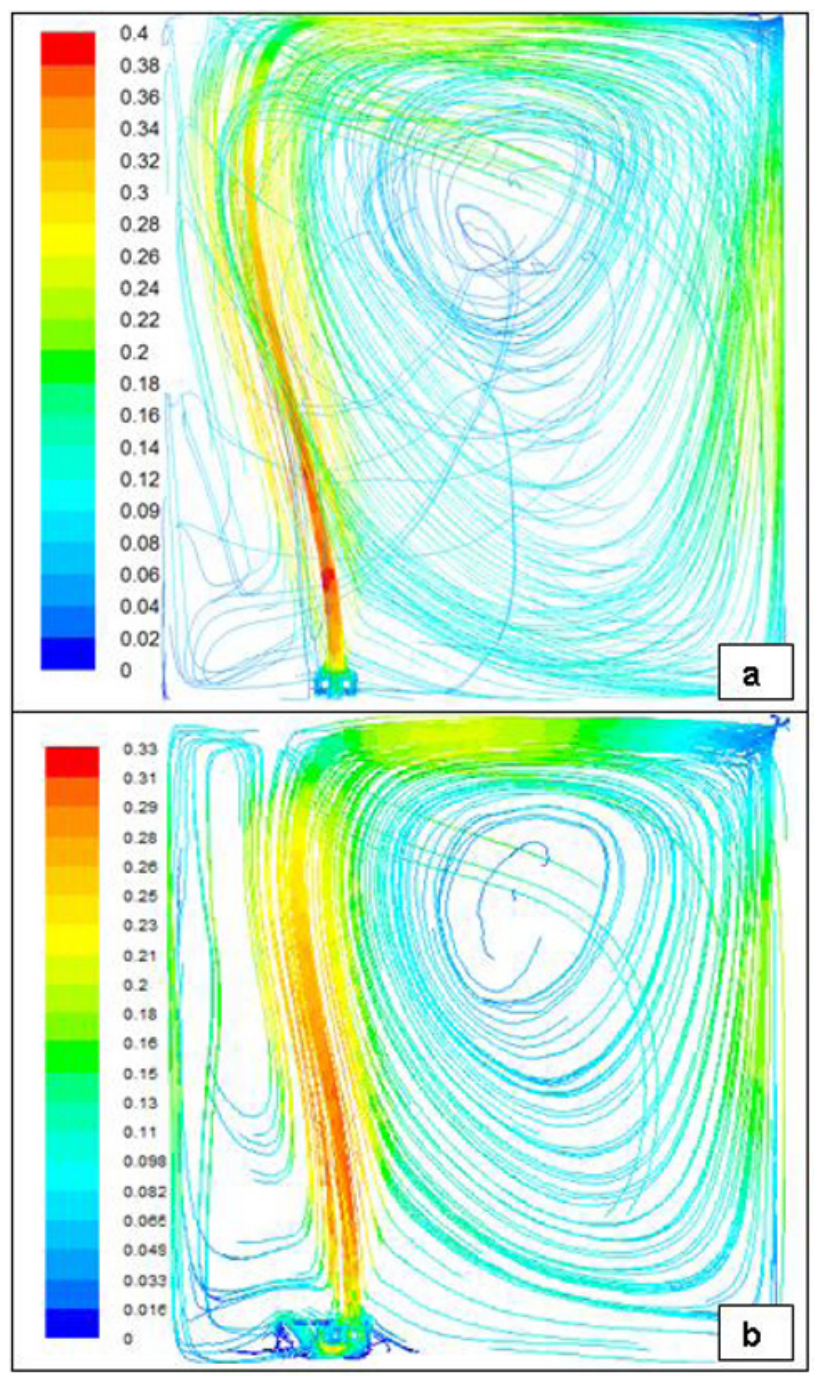

Fig. 3. Air flow trajectory with velocity contours a-sample without housing, b-sample with housing

The last measurement we made dealt with the influence of tilt both sides on thermal performance of floor convector. We changed the tilt both of sides at the same in the range from 0 to 90 degrees. As a result is a Graph 4, where is illustrated the thermal performance depending on the tilt of both sides of tub floor convector. From Graph 4 shows, as in previous case, that the performance of floor convector is highest when the tub is fully opened and lowest when is fully closed. The influence of tub floor convector on heat transfer from floor convector, we can see in figure 4 and figure 5, when are shown visualization of temperature areas from sample of floor convector, made in Ansys 12.0. Comparing the figures we see a significant impact of tub on the flow of air to the surrounding.

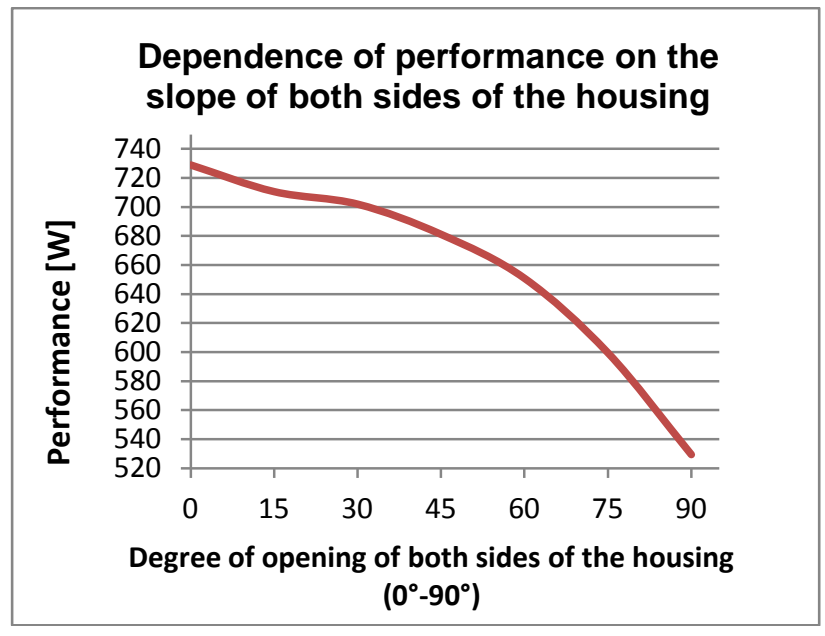

Graph 4 Floor convector performance in dependence of the slope of the housing both sides

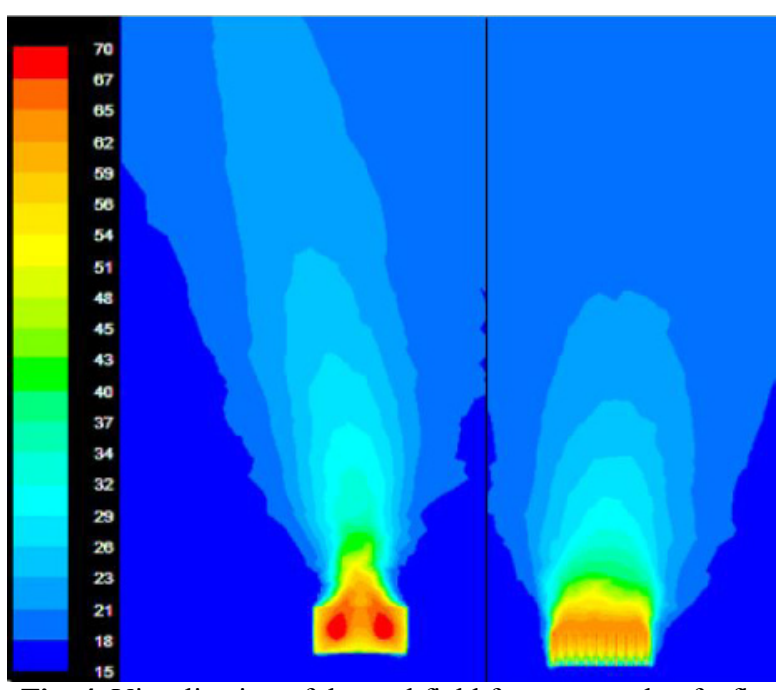

Fig. 4. Visualization of thermal field from a sample of a floor convector without housing

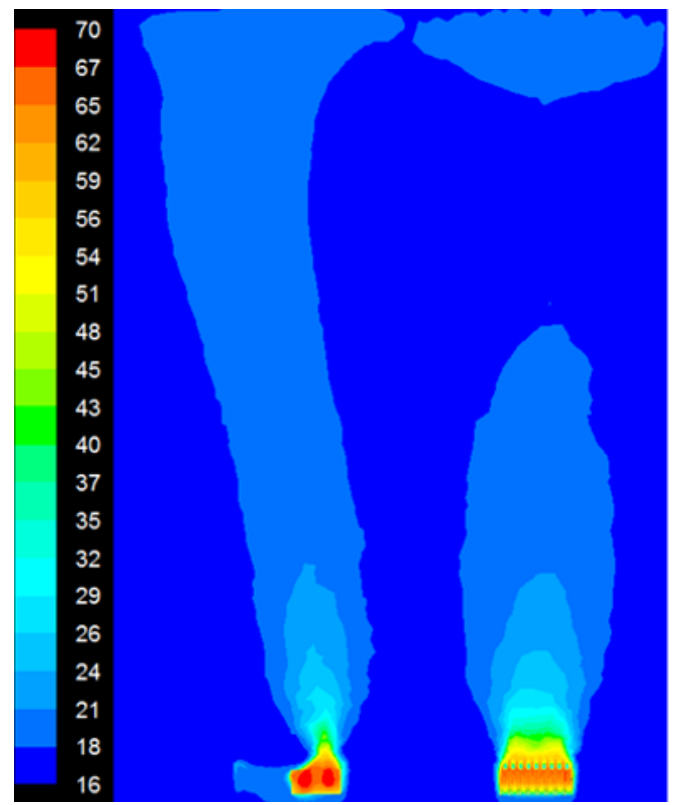

Fig. 5. Visualization of thermal field from a sample of a floor convector with housing 


\section{Conclusion}

From the analysis of individual measurements revealed, that the performance of floor convector type BK $2 \mathrm{E} / 270-112-2000$ with natural convection is considerably affected by the geometry of the tub convector. When was fully opened the front of tub, the thermal performance reached a value $648.88 \mathrm{~W}$ and when was fully closed a value $536.75 \mathrm{~W}$. Thermal performance when the back part of tub was fully opened, reached a value $636.38 \mathrm{~W}$ and with fully closed a value $528.56 \mathrm{~W}$. Thermal performances with a change of tilt both sides of tub convector reached value $729 \mathrm{~W}$ in fully opened and $529.38 \mathrm{~W}$ in fully closed of tub convector.

\section{Acknowledgement}

This paper was created within the project VEGA-

$1 / 1127 / 11$.

\section{References}

1. R. Remsburg. Thermal design of electronic equipment. Boca Raton:CRC Press LLC, 2001

2. P. Incopera, P. Dewit. Fundamentals heat and mass transfer. 6st. ed. John Wiley, New York, 2007

3. Shang, Deyi: Free Convection Film Flows and Heat Transfer. Springer Berlin Heidelberg, New York, 2006.

4. A. Kapjor, R. Lenhard,: Simulation of Convective Heat Transfer by Passive Roof Cooling Convectors. Published by University of Žilina, Transcom 2007.

5. R. Lenhard, S. Gavlas. CFD simulation of passive the chilled beam in a room. In: ERIN 2011 education, research, innovation: proceedings of 5th conference for young researchers and $\mathrm{PhD}$ students : 13th-16th April 2011 - Tatranská Kotlina - Vysoké Tatry - Slovakia. - Prešov: Harmony Apeiron, 2011

6. R. Lenhard, J. Jandačka. Numerical Modeling of Passive Roof Cooling Convectors In: Fluid dynamics 2008 colloquium: proceedings Prague, October 2224, 2008, Czech Republic. - Prague: Institute of Thermomechanics, Academy of Sciences of the Czech Republic, 2008 